\title{
Genomic amplification of MYC as double minutes in a patient with APL-like leukemia
}

Pino J Poddighe ${ }^{1 *}$, Hans Wessels ${ }^{1}$, Pauline Merle ${ }^{2}$, Marisa Westers², Shama Bhola', Anne Loonen², Sonja Zweegman², Gert J Ossenkoppele ${ }^{2}$ and Marielle J Wondergem²

\begin{abstract}
Background: Acute promyelocytic leukemia (APL) is a subtype of acute myeloid leukemia (AML) characterized by a PML-RARA fusion due to a translocation $\mathrm{t}(15 ; 17)$. Its sensitivity to treatment with all-trans retinoic acid (ATRA), which causes differentiation of the abnormal promyelocytes, combined with anthracycline based chemotherapy makes it the best curable subtype of acute myeloid leukemia. A rapid and accurate diagnosis is needed in the first place to prevent (more) bleeding problems. Here we present a patient with a leukemia with an APL-like morphology but no detectable PML-RARA fusion, as demonstrated by RT-PCR and cytogenetic analysis.
\end{abstract}

Results: Unexpectedly, karyotyping revealed numerous double minutes (dmins). Fluorescence in situ hybridization (FISH) with DNA probes specific for the MYC-region showed the presence of multiple MYC amplicons. SNP-array analysis uncovered amplification of the 8q24.13-q24.21 region, including the MYC-gene, flanked by deletions in $8 q 24.13$ and 8q24.21-q24.22, and a homozygous deletion in 9p21.3, flanked by heterozygous deletions in the same chromosome region.

Conclusions: The diagnosis was revised to AML, not otherwise specified (AML, NOS) and therefore therapy with ATRA was discontinued.

Keywords: Acute promyelocytic leukemia, MYC, Double minutes, Cytogenetics, SNP-array

\section{Background}

Acute promyelocytic leukemia (APL) is a hematological emergency frequently associated with severe coagulation disturbances. The typical morphology shows abnormal, usually bilobed hypergranular promyelocytes. In some cases the cytoplasmic granules are so large or numerous that they completely fill the cell, obscuring the nuclear cytoplasmic limit. Frequently characteristic cells containing bundles of Auer rods, the so-called faggot cells, are seen. In APL, Sudan Black (SB) or myeloperoxidase (MPO) is always strongly positive in all blast cells, with the reaction product covering the whole cytoplasm and often the nucleus too [1].

Cytogenetically a reciprocal translocation $\mathrm{t}(15 ; 17)$ (q24; q21) is present, leading to a fusion gene consisting of the proximal part of the promyelocytic leukemia gene (PML) on 15q24 and the distal part of the retinoic acid

\footnotetext{
* Correspondence: p.poddighe@vumc.nl

'Department of Clinical Genetics, VU University Medical Center, De Boelelaan 1117, PK 0X011, Amsterdam 1081 HV, The Netherlands

Full list of author information is available at the end of the article
}

receptor alpha $(R A R A)$ gene usually on $17 \mathrm{q} 21$ [2]. This has therapeutic impact, since APL with a $t(15 ; 17)$ has a particular sensitivity to treatment with all-trans retinoic acid (ATRA). Treatment with ATRA, combined with cytotoxic chemotherapy or arsenic trioxide (ATO) results in complete remission rates of over 90\% [3]. The high morbidity and mortality associated with the coagulation abnormality already present in most patients at diagnosis requires that ATRA must be initiated immediately after the diagnosis is suspected.

Rare cases of APL with typical morphology lack the classic translocation in routine cytogenetic studies. They may still express the $P M L-R A R A$ transcript due to a cryptic $P M L-R A R A$ fusion gene e.g. as a result of an insertion of the RARA gene near the PML gene on 15q24. These APL have the same response to ATRA as the classical or hypergranular APL.

Another subgroup of APL, the so-called variant or hypogranular APL, has the typical translocation $\mathrm{t}(15 ; 17)$ and is also ATRA responsive, but usually presents with a leukocytosis, which may increase quickly. In these 
hypogranular cases the characteristic cells are not promyelocytes but bilobed blasts with seemingly absent granules and infrequent faggot cells and a strong positive SB or MPO reaction [4].

In the present study we present a case that morphologically resembled a classic APL and was treated as such. The diagnosis had to be reconsidered when additional investigations showed an unexpected cytogenetic result.

\section{Case presentation}

A 76-year-old man presented with exertional dyspnea, visual disturbances, night sweats and progressive fatigue. His medical history showed chronic obstructive pulmonary disease, Diabetes Mellitus type 2, hypercholesterolemia and alcohol abuse. On physical examination he had some petechiae and hematoma on the lower extremities. No lymphadenopathy or organomegaly was found. His white blood cell count was extremely elevated $(220 \times$ $\left.10^{9} / \mathrm{l}\right)$. Hemoglobin was $6.5 \mathrm{mmol} / \mathrm{l}$ and platelets were $20 \times 10^{9} /$ l. The peripheral blood smear revealed $37 \times$ $10^{9} / 1$ blasts, with Auer rods, but also $78 \times 10^{9} / 1$ promyelocytes, with some faggot cells, resembling typical APL (Figure 1A). Other abnormal laboratory findings included a LDH of $5230 \mathrm{U} / \mathrm{l}$ and creatinine of 130 micro$\mathrm{mol} / \mathrm{l}$. No coagulation abnormalities were present.

Since he had signs of leukostasis (dyspnea, visual disturbances and tinnitus) he was immediately treated with leukapheresis in addition to the administration of daunorubicin $\left(45 \mathrm{mg} / \mathrm{m}^{2}\right)$ and, because of the typical APL morphology, ATRA ( $45 \mathrm{mg} / \mathrm{m}^{2}$ in two doses per day).

\section{Methods}

\section{Immunophenotyping}

Flow cytometric analysis of the peripheral blood was performed according to standard guidelines for immunophenotyping of acute leukemia with some modifications (www.cytometrie.nl). An eight-color antibody panel was applied; data were acquired on a FACSanto II flow cytometer and analyzed with FACS-DIVA software (BD Biosciences, San José, CA, USA).

\section{Cytogenetic studies}

The patient's peripheral blood was set up in two 24-hour RPMI 1640 cultures, one unstimulated and one stimulated with growth factors G/CSF, IL3 and GM/CSF. After standard cytogenetic harvesting and GTG banding 20 metaphase cells were analyzed from the stimulated culture. The karyotype was described according to ISCN 2013 [5].

Fluorescence in situ hybridization (FISH) using directly labeled probes was performed according to the manufacturer's instructions in combination with our established laboratory protocol. The following probes were used: Vysis LSI PML/RARA Dual Color Dual Fusion Probe
(Abbott Molecular IL, Hoofddorp, The Netherlands), ON MYC/IGH t $(8 ; 14)$ Fusion Probe (Kreatech, Amsterdam, The Netherlands), and the BAC probes RP11-150N13 [Chr8:126,376,029-126,557,325 Mb(hg19)], RP11-495D4 [Chr8:126,530,000-126,729,672 Mb(hg19)], RP11-367L7 [Chr8:128,459,593-128,628,028 Mb(hg19)], RP1-80K22 [Chr8:128,667,455-128,814,588 Mb(hg19)], RP11-125A17 [Chr8:128,865,417-129,036,660 Mb(hg19)], RP11-316E19 [Chr8:133,852,795-134,111,178 Mb(hg19)] and RP11268C19 [Chr8:134,410,759-134,585,494 Mb(hg19)] from BlueGnome Ltd, Cambridge, UK.

\section{Molecular diagnostics}

RNA was isolated from mononuclear blood cells, using RNAeasy (Qiagen). cDNA synthesis of $1 \mu \mathrm{g}$ RNA was performed using M-MLV (Invitrogen) and random hexamer primers (Roche). PML-RARa fusion transcripts were amplified using RT-PCR according to Miller et al. [6]. PCR products were analyzed on agarose gel. FLT3ITD RT-PCR followed by GeneScan analysis was done as described previously [7].

\section{Genomic profiling and data analysis}

Microarray-based genomic profiling was carried out with $250 \mathrm{ng}$ DNA isolated from peripheral blood using the CytoScan HD array platform (Affymetrix, Inc., Santa Clara, CA, USA) and was performed according to the manufacturer's protocol. The data obtained by the CytoScan HD array platform were analyzed using Nexus copy number software (Biodiscovery Inc., Hawthorne, CA, USA) and annotations of genome version GRCh37 (hg19).

\section{Results}

Immunophenotyping showed a cell population that was CD34 negative and positive for CD117, HLA-DR, MPO and $\mathrm{CD} 15$, with heterogeneous expression of CD33+ and weak expression of CD13, CLIP expression was absent, and a second cell population with more monocytic characteristics: positive for CD11b, CD11c, and aberrantly CD56.

Karyotyping revealed an abnormal male karyotype, but instead of a translocation $t(15 ; 17)$ the cells showed 7 to 50 dmins (see Figure 1B): 46,XY,7 50dmin[20]. Interphase FISH with the LSI PML/RARA DC DF probe showed no PML-RARA fusion in 200 cells (results not shown). Molecular analysis revealed that both $P M L-$ $R A R a$ fusion and FLT3 were negative. Since double minutes in AML have mostly been described as consisting of $M Y C$, we performed FISH with the DNA probe ON MYC/IGH $t(8 ; 14)$ Fusion Probe. This probe indeed showed that the dmins stained positive for $M Y C$ (Figure 1C). Furthermore, the MYC-probe signal was only present on one chromosome 8, indicating loss of the $M Y C$ region from 


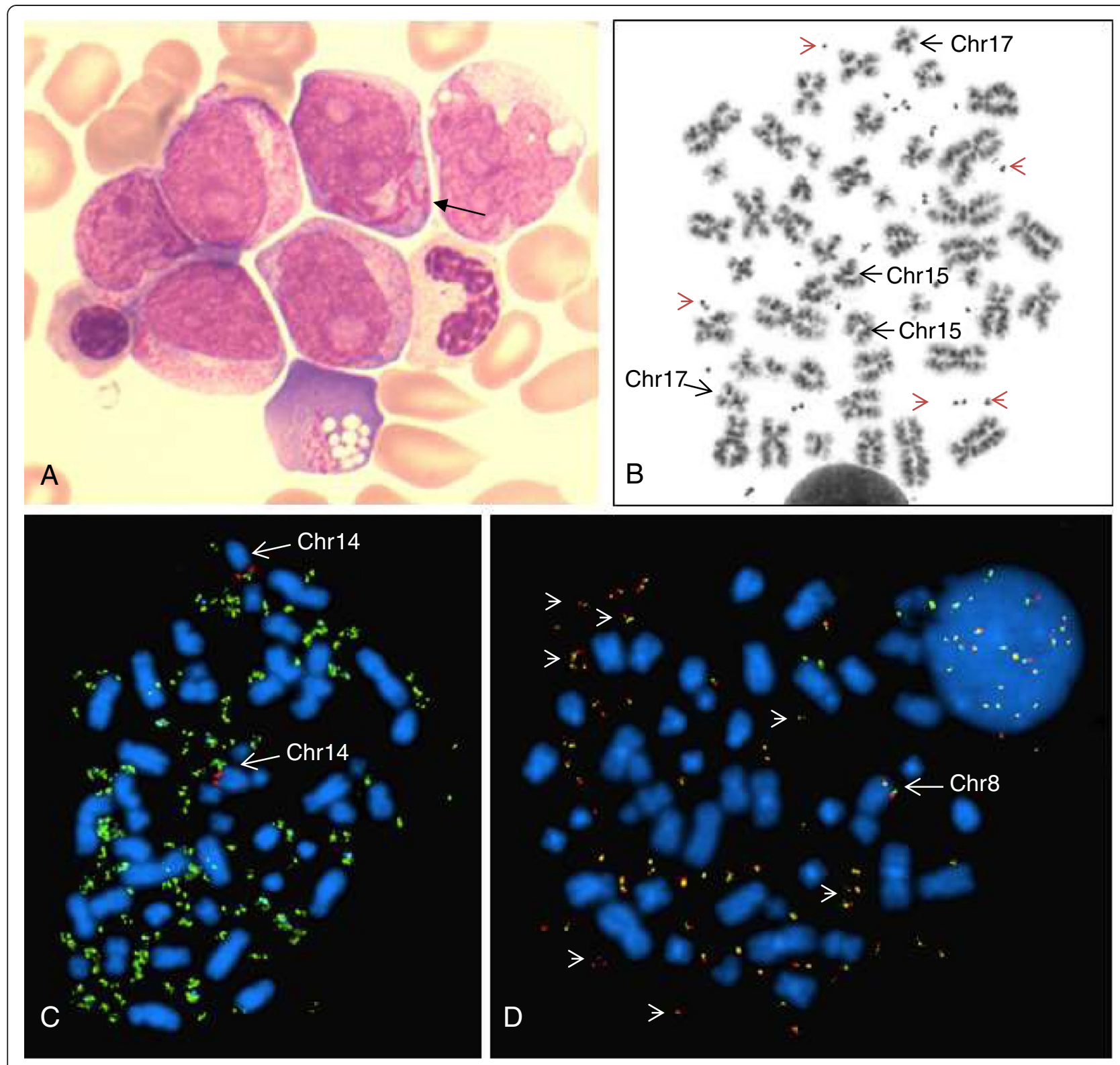

Figure 1 Cytomorphologic and cytogenetic results. (A) A representative cytomorphologic bone marrow field, showing blasts with Auer rods (arrow) and azurophilic inclusions. (B) A representative metaphase cell demonstrating normal chromosomes 15 and 17, and more than 20 double minutes (red arrowheads). (C) Metaphase FISH of this patient with the ON MYC(green)/IGH(red) t(8;14) Fusion Probe (Kreatech), showing MYC-positive dmins (green), and both chromosomes 14 (arrow); in this cell it was not possible to indicate the normal chromosome 8 due to the high number of dmins (D) Metaphase FISH with a BAC-probe RP1-80K22 (base pair position 128,667,455-128,814,588) for MYC gene (red) and a flanking BAC-probe RP11-125A17 (base pair position 128,865,417-129,036,660; green), demonstrating multiple copies of dmins (red-green signals). Only one chromosome 8 (arrow) contains the MYC gene region.

the other chromosome 8 (see Figure 1D). The karyotype was therefore adjusted: 46,XY,7-50dmin[20].ish del(8) (q24.2q24.2)(MYC-), dmin(MYCx7 50)[10].

Genome-wide SNP array analysis revealed an amplification of 4,56 Mb on 8q24.13-q24.21, which contained 15 genes, including $M Y C$, flanked by a proximal deletion at $8 \mathrm{q} 24.13$ of $693 \mathrm{~kb}$ (10 genes) and a distal deletion at $8 q 24,21$ of 1,07 Mb (6 genes) (see Figure 2A and Table 1).
On 9p21.3 a deletion of 2,28 Mb (31 genes) was observed, of which $442 \mathrm{~kb}$ was homozygous (see Figure $2 \mathrm{~B}$ and Table 1).

Additional FISH with the probe combination RP1$80 \mathrm{~K} 22$ (overlapping the $M Y C$-gene) and a distal flanking BAC-probe RP11-125A17 confirmed that the dmins contained more than the $M Y C$-gene (see Figure 1D). The proximal flanking DNA probes RP11-150N13, 


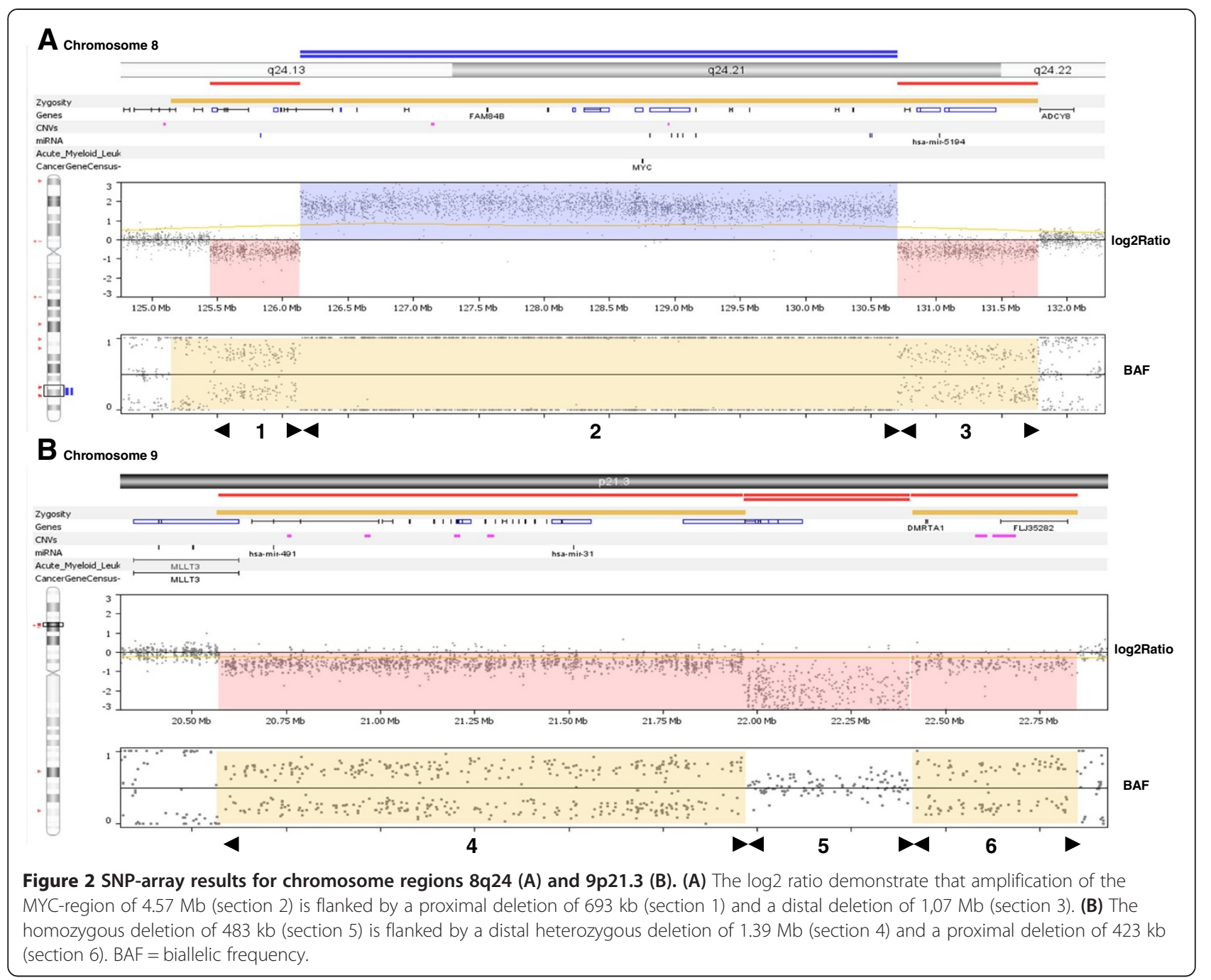

Table 1 Overview of genomic aberrations detected by SNP-array

\begin{tabular}{lllll}
\hline $\begin{array}{l}\text { Chromosome } \\
\text { region }\end{array}$ & Genomic position & Length (base pairs) & Copy number & Gene symbol \\
\hline $8 q 24.13 q 24.13$ & $125,444,383-126,137,622$ & 693.240 & Deletion & $\begin{array}{l}\text { TRMT12, RNF139, TATDN1, NDUFB9, MTSS1, LOC157381, } \\
\text { ZNF572, SQLE, KIAA0196, NSMCE2 }\end{array}$ \\
$8 q 24.13 q 24.21$ & $126,137,622-130,706,799$ & 4.569 .178 & Amplification & $\begin{array}{l}\text { NSMCE2, TRIB1, LOC100130231, FAM84B, PCAT1, POU5F1B, } \\
\text { LOC727677, MYC, MIR1204, MIR1205, PVT1, MIR1206, } \\
\end{array}$ \\
& & & MIR1207, MIR1208, LOC728724 \\
$8 q 24.21 q 24.22$ & $130,706,799-131,782,618$ & 1.075 .820 & Deletion & GSDMC, FAM49B, MIR5194, LOC100507117, ASAP1, ASAP1-IT1 \\
$9 p 21.3 p 21.3$ & $20,571,017-21,966,002$ & 1.394 .986 & Deletion & MLLT3, MIR491, FOCAD, PTPLAD2, IFNB1, IFNW1, IFNA21, \\
& & & & IFNA4, IFNA7, IFNA10, IFNA16, IFNA17, IFNA14, IFNA22P, \\
& & & IFNA5, KLHL9, IFNA6, IFNA13, IFNA2, IFNA8, IFNA1, IFNE, \\
$9 p 21.3 p 21.3$ & $21,966,002-22,408,814$ & 442.813 & Homozygous deletion & C90rf53, CDKN2A, CDKN2B, CDKN2B-AS1 \\
$9 p 21.3 p 21.3$ & $22,408,814-22,851,531$ & 442.718 & Deletion & DMRTA1, FLJ35282 \\
\hline
\end{tabular}


RP11-495D4 and RP11-367L7 were also present on the dmins, whereas the distal flanking DNA probes RP11-316E19 and RP11-268C19 were absent (results not shown).

The final karyotype we decided on was 46,XY,7-50dmin [20].ishdel(8)(q24.2q24.2)(MYC-),dmin(MYCx7 50)[10]. arr 8q24.13(125,444,383-126,137,622)x1,8q24.13q24.21 (126,137,622-130,706,799)amp,8q24.21q24.22(130,706, 799-131,782,618)x1,9p21.3(20,571,017-21,966,002)x1, 9p21.3(21,966,002-22,408,814)x0,9p21.3(22,408,814-22, 851,531)x1.

Following leukapheresis and administration of daunorubicin leucocyte counts dropped to $0.910^{9} / 1$. Based on the additional investigations the diagnosis of APL was altered to AML, not otherwise specified (AML, NOS) [4].

The patient's age and physical condition didn't allow to deliver intensive anti-leukemic chemotherapy. He subsequently developed a paralytic ileus and hypotension and died.

\section{Conclusions}

In this report we describe a patient with a rare APL-like phenotype. At presentation the peripheral blood smears showed a typical APL morphology. However, immunophenotyping results were not typical for APL, that is usually HLADR negative with homogeneous expression of CD33 and CLIP positive [8]. Moreover, the extreme leukocytosis and also the absence of abnormal coagulation tests did not fit in with the diagnosis of APL. In hypogranular APL the leucocyte count can be very high with a rapid doubling time, but the patient's cell morphology and immunophenotyping didn't resemble a hypogranular APL. The additional investigations confirmed this; there was no detectable $P M L-R A R A$ fusion product present. In fact, cytogenetic analyses showed no $\mathrm{t}(15 ; 17)$, but the presence of 7 to 50 double minutes (dmins). SNP-array identified a 4,56 Mb large amplicon (containing 15 genes), flanked by a proximal deletion of $693 \mathrm{~kb}$ (10 genes) and a distal deletion of approximately 1,07 $\mathrm{Mb}$ (6 genes), as well as a homozygous deletion in 9 p21.3 of $443 \mathrm{~kb}$ (4 genes), which was flanked by two heterozygous deletions: one distal deletion of about 1,4 $\mathrm{Mb}$ (25 genes) and one proximal deletion of $443 \mathrm{~kb}(2$ genes), see Table 1.

Amplification of human chromosome region $8 \mathrm{q} 24$ has been associated with many types of solid tumors, such as breast, prostate, colon, lung, ovaries and pancreas [9-11]. The genes in this region are mostly all oncogenes or tumor suppressor genes, affecting general cancer susceptibility. In general, the $M Y C$-gene is involved in this amplification and can be present as dmins or homogeneously staining regions (hsr). Gene amplification in AML is rare, the most frequent gene involved being $M Y C$ and the second most common oncogene MLL
[12], mostly as part of a complex karyotype. MYC amplification manifesting as dmins has been described in only a few cases with an APL or APL-like morphology [13-15].

In solid tumors, such as colon, pancreatic and breast carcinomas, brain tumors and neuroblastomas, dmins can be observed as a late genomic event in tumorigenesis, the dmins being associated with a rapid cellular growth and poor prognosis. In AML dmins appear less frequently, in about $1 \%$ of the cases $[12,16,17]$. The mechanism of the excision of DNA segments from an otherwise intact chromosome, followed by circularization and amplification by mutual recombination to produce dmins, has been described by Carroll et al. [18]. Storlazzi et al. [19] have provided evidence for this so-called episomal model for the formation of MYCcontaining dmin in acute myeloid leukemia.

The deletion in $8 \mathrm{q}$ was larger than the amplified segment in dmins, and this phenomenon was also observed in a study by Storlazzi et al. [20], who describe a chromosomal deletion in $8 \mathrm{q} 24$ corresponding to or larger than the amplicon in $68 \%$ of 34 investigated AML/ MDS cases, suggesting post-replicative excision of DNA followed by circularization (episome) as the mechanism behind the dmin formation.

The first patient with MYC amplification in dmins as the sole cytogenetic aberration has been described by Frater et al. [15]. Also in our patient the excision of $M Y C$ from $8 \mathrm{q} 24$ with subsequent amplification of this region into dmins may have led to upregulation of the expression of the $M Y C$ oncogene, a known critical nuclear transcription factor.

Deletions of $9 \mathrm{p}$ are not frequent recurrent chromosome aberrations in AML. Usvasalo et al. [21] reported a study in which multiple areas of copy number loss, or homozygous loss within a larger heterozygous loss region, in 9p was restricted to ALL patients, and was not observed in AML patients. Interestingly, the APL-like patient without a PML-RARA fusion presented by Bruyère et al. [13] showed $M Y C$ amplification as dmins and an apparently terminal deletion of the short arm of chromosome 9 with the breakpoint at band p21. Our findings support their suggestion that there might be an association between loss of $9 p$, dmins, and an APL-like morphology.

In summary, we describe a patient with an APL-like morphology, who showed no PML-RARA fusion but $M Y C$ amplification in dmins. It is of utmost importance to have a rapid confirmation or exclusion of $t(15 ; 17)$ in an acute leukemia that morphologically resembles APL. Therefore, in our routine practice we have implemented a rapid, four hours interphase FISH test using a LSI PML/RARA DC DF Probe (Vysis) on bone marrow or blood smears from patients suspected for APL. In 
contrast to the other similar reported case [15] our patient died soon after diagnosis from abdominal sepsis before proper treatment could be initiated.

\section{Consent}

Informed consent was obtained from the patient for the publication of this report and any accompanying images.

\section{Abbreviations}

AML NOS: Acute myeloid leukemia, not otherwise specified; APL: Acute promyelocytic leukemia; ATO: Arsenic trioxide; ATRA: All-trans retinoic acid; dmins: Double minutes; BAC: Bacterial artificial chromosome;

FISH: Fluorescence in situ hybridization; MPO: Myeloperoxidase;

PML: Promyelocytic leukemia gene; RARA: Retinoic acid receptor alpha gene; SB: Sudan Black; SNP: Single nucleotide polymorphism.

\section{Competing interests}

The authors declare that they have no competing interests.

\section{Authors' contributions}

PJP drafted the paper and participated in the molecular cytogenetic studies, AL performed the morphology and cytochemistry, MW carried out the immunophenotyping, HW performed karyotyping, FISH and SNP-array experiments, PM was involved in the molecular diagnostic studies, SB contributed in interpretation of the cytogenetic data, SZ was involved in treatment of the patient, $\mathrm{SZ}$ and $\mathrm{GO}$ have made contributions to conception and design of the paper, and MW participated in the design and coordination of the study and helped to draft the manuscript. All authors read and approved the final manuscript.

\section{Acknowledgements}

We thank A. Nieuwint for critical readings and comments on the manuscript.

\section{Author details}

${ }^{1}$ Department of Clinical Genetics, VU University Medical Center, De Boelelaan 1117, PK OX011, Amsterdam 1081 HV, The Netherlands. ${ }^{2}$ Department of Haematology, VU University Medical Center, Amsterdam, The Netherlands.

Received: 28 July 2014 Accepted: 27 September 2014

Published online: 22 October 2014

\section{References}

1. Huret JL, Chomienne C: t(15;17)(q24;q21). Atlas Genet Cytogenet Oncol Haematol 1998, 2(3):101-103.

2. Rowley JD, Golomb HM, Dougherty C: $15 / 17$ translocation, a consistent chromosomal change in acute promyelocytic leukaemia. Lancet 1977, 1:549-550.

3. Lo-Coco F, Avvisati G, Vignetti M, Thiede C, Orlando SM, lacobelli S, Ferrara F, Fazi P, Cicconi L, Di Bona E, Specchia G, Sica S, Divona M, Levis A, Fiedler W, Cerqui E, Breccia M, Fioritoni G, Salih HR, Cazzola M, Melillo L, Carella AM, Brandts $\mathrm{CH}$, Morra E, von Lilienfeld-Toal M, Hertenstein B, Wattad M, Lübbert $M$, Hänel M, Schmitz N, et al: Retinoic acid and arsenic trioxide for acute promyelocytic leukemia. N Engl J Med 2013, 369(2):111-121.

4. Arber DA, Brunning RD, Le Beau MM, Falini B, Vardiman JW, Porwit A, Thiele J, Bloomfield CD: Chapter 6: Acute Myeloid Leukaemia and Related Precursor Neoplasms. In WHO Classification of Tumours of Haematopoietic and Lymphoid Tissues. Edited by Swerdlow SH, Campo E, Harris NL, Jaffe ES, Pileri SA, Stein H, Thiele J, Vardiman JW. Lyon: IARC; 2008:109-139.

5. Shaffer LG, McGowan-Jordan J, Schmid M (Eds): ISCN 2013: an international system for human cytogenetic nomenclature. Basel: Karger; 2013.

6. Miller WH Jr, Levine K, DeBlasio A, Frankel SR, Dmitrovsky E, Warrell RP Jr: Detection of minimal residual disease in acute promyelocytic leukemia by a reverse transcription polymerase chain reaction assay for the PML/RAR-alpha fusion mRNA. Blood 1993, 82(6):1689-1694.

7. Nakao M, Yokota S, Iwai T, Kaneko H, Horiike S, Kashima K, Sonoda Y, Fujimoto T, Misawa S: Internal tandem duplication of the flt3 gene found in acute myeloid leukemia. Leukemia 1996, 10:1911-1918.
8. van Luijn MM, Westers TM, Chamuleau ME, van Ham SM, Ossenkoppele GJ, van de Loosdrecht AA: Class II-associated invariant chain peptide expression represents a novel parameter for flow cytometric detection of acute promyelocytic leukemia. Am J Pathol 2011, 179(5):2157-2161.

9. Ghoussaini M, Song H, Koessler T, Al Olama AA, Kote-Jarai Z, Driver KE, Pooley KA, Ramus SJ, Kjaer SK, Hogdall E, DiCioccio RA, Whittemore AS, Gayther SA, Giles GG, Guy M, Edwards SM, Morrison J, Donovan JL, Hamdy FC, Dearnaley DP, Ardern-Jones AT, Hall AL, O'Brien LT, Gehr-Swain BN, Wilkinson RA, Brown PM, Hopper JL, Neal DE, Pharoah PD, Ponder BA, et al: Multiple loci with different cancer specificities within the 8q24 gene desert. J Nat/ Cancer Inst 2008, 100:962-966.

10. Storlazzi CT, Lonoce A, Guastadisegni MC, Trombetta D, D'Addabbo P, Daniele G, L'Abbate A, Macchia G, Surace C, Kok K, Ullmann R, Purgato S, Palumbo O, Carella M, Ambros PF, Rocchi M: Gene amplification as double minutes or homogeneously staining regions in solid tumors: Origin and structure. Genome Res 2010, 20:1198-1206.

11. Takahashi Y, Sawada G, Kurashige J, Uchi R, Matsumura T, Ueo H, Takano Y, Eguchi H, Sudo T, Sugimachi K, Yamamoto H, Doki Y, Mori M, Mimori K: Amplification of PVT-1 is involved in poor prognosis via apoptosis in colorectal cancers. Br J Cancer 2014, 110(1):164-171.

12. Thomas L, Stamberg J, Gojo I, Ning Y, Rapoport AP: Double minute chromosomes in monoblastic (M5) and myeloblastic (M2) acute myeloid leukaemia: two case reports and a review of the literature. Am J Hematol 2004, 77:55-61.

13. Bruyère $H$, Sutherland $H$, Chipperfield $K$, Hudoba M: Concomitant and successive amplifications of MYC in APL-like leukaemia. Cancer Genet Cytogenet 2010, 197:75-80.

14. Zuberi L: Rapid response to induction in a case of acute promyelocytic leukaemia with MYC amplification on double minutes at diagnosis. Cancer Genet Cytogenet 2010, 198(2):170-172.

15. Frater JL, Hoover RG, Bernreuter K, Batanian JR: Deletion of MYC and presence of double minutes with MYC amplification in a morphologic acute promyelocytic leukaemia-like case lacking RARA rearrangement: could early exclusion of double-minute chromosomes be a prognostic factor? Cancer Genet Cytogenet 2006, 166:139-145.

16. Li YS: Double minutes in acute myeloid leukemia. Int J Cancer 1983, 32:455-459.

17. Bruckert P, Kappler R, Scherthan H, Link H, Hagmann F, Zankl H: Double minutes and c-MYC amplification in acute myelogenous leukemia: Are they prognostic factors? Cancer Genet Cytogenet 2000, 120:73-79.

18. Carroll SM, DeRose ML, Gaudray P, Moore CM, Needham-Vandevanter DR, Von Hoff DD, Wahl GM: Double minute chromosomes can be produced from precursors derived from a chromosomal deletion. Mol Cell Biol 1988, 8:1525-1533.

19. Storlazzi CT, Fioretos $T$, Surace $C$, Lonoce A, Mastrorilli A, Strömbeck $B$, D'Addabbo P, lacovelli F, Minervini C, Aventin A, Dastugue N, Fonatsch C, Hagemeijer A, Jotterand M, Mühlematter D, Lafage-Pochitaloff M, Nguyen-Khac F, Schoch C, Slovak ML, Smith A, Solè F, Van Roy N, Johansson B, Rocchi M: MYC-containing double minutes in hematologic malignancies: evidence in favor of the episome model and exclusion of MYC as the target gene. Hum Mol Genet 2006, 15(6):933-942.

20. Storlazzi CT, Fioretos T, Paulsson K, Strömbeck B, Lassen C, Ahlgren T, Juliusson G, Mitelman F, Rocchi M, Johansson B: Identification of a commonly amplified $4.3 \mathrm{Mb}$ region with overexpression of C8FW, but not MYC in MYC-containing double minutes in myeloid malignancies. Hum Mol Genet 2004, 13(14):1479-1485.

21. Usvasalo A, Ninomiva S, Räty R, Hollmén J, Saarinen-Pihkala UM, Elonen E, Knuutila S: Focal 9p instability in hematologic neoplasias revealed by comparative genomic hybridization and single-nucleotide polymorphism microarray analyses. Genes Chromosomes Cancer 2010, 49(4):309-318.

\section{doi:10.1186/s13039-014-0067-6}

Cite this article as: Poddighe et al:: Genomic amplification of MYC as double minutes in a patient with APL-like leukemia. Molecular Cytogenetics 2014 7:67. 